\title{
Nodos: Encyclopedia of the Performing Arts
}

\section{Nodos: Enciclopedia de las Artes Escénicas}

\author{
Diego Torres ${ }^{1}$ (D), Alicia Diaz ${ }^{1,}$ Virginia Cepeda² ${ }^{2}$ Facundo Correa ${ }^{2}$, Alejandro Fernandez ${ }^{1}$ (D) \\ ${ }^{1}$ LIFIA, Centro Asociado CIC, Facultad de Informática, Universidad Nacional de La Plata, La Plata, Argentina \\ ${ }^{2}$ Licenciatura en Sistemas, Facultad de Informática, Universidad Nacional de La Plata, La Plata, Argentina \\ diego.torres@ lifia.info.unlp.edu.ar, alicia.diaz@lifia.info.unlp.edu.ar, virginiamcepeda@gmail.com, \\ $\underline{\text { fcorrea.open@gmail.com, alejandro.fernandez@ lifia.info.unlp.edu.ar }}$
}

(Received: 10 November 2017, accepted: 15 December 2017)

\begin{abstract}
The main goal of Nodos is to promote the collective creation of semantic knowledge regarding performing arts. Recording and curating information about these expressions contributes to the preservation of the Intangible Cultural Heritage, as defined by UNESCO. One of the challenges related to the preservation of information is the large amount of people involved in the creation and development of scenic arts and the dynamism in these theater pieces. The large number of plays presented every year makes it difficult to keep records up to date, resulting in the loss of knowledge about many cultural pieces. This article introduces a way to record such cultural heritage in the context of a citizen science project. Nodos defines an ontology regarding performing arts and also uses a semantic wiki that helps in the implementation of the ontology. An evaluation of usability shows Nodos as an effective initiative to preserve and study performing arts.
\end{abstract}

Keywords: Semantic Wiki, Intangible Cultural Heritage, Performing arts ontology.

\begin{abstract}
Resumen. Nodos es un proyecto que posee como objetivo promover y generar una exhaustiva base de conocimiento sobre artes performáticas. El registro de este tipo de artes contribuye a la preservación del Patrimonio Cultural Intangible definido por UNESCO. Uno de los desafíos está dado por la gran cantidad de personas vinculadas y el dinamismo que presentan las obras. La dificultad de documentar las numerosas obras presentadas cada año conlleva la pérdida de los registros de muchas de las obras. En este artículo se presenta una forma de registrar ese tipo de patrimonio cultural en el contexto de un proyecto de ciencia ciudadana. Específicamente, por medio de la definición de una ontología sobre las artes escénicas y la utilización de una wiki semántica. Finalmente, una evaluación de usabilidad muestra que Nodos es una iniciativa efectiva para preservar y estudiar a las artes escénicas.
\end{abstract}

Palabras clave: Wiki semántica, Patrimonio Cultural Intangible, Ontología en artes escénicas.

\section{Introduction}

During the last years, GEC $^{1}$ group (Grupo de Estudio sobre Cuerpo) at Universidad Nacional de La Plata has built a performing arts catalogue. The catalogue is updated on yearly basis and it records information about the different stakeholders (such as actors, dancers, or theaters) that compose the performing arts scene in the city of La Plata, Argentina. Latterly, GEC has tried to complete information manually, to continue with manual processes for data collection and to create the catalog using a three-step process: surveying, content curation and final compilation. However, several artists, groups, and plays are so many and so diverse that using this three-step process was sometimes impossible to be performed on time, and consequently having direct implications such as outdated versions of the catalog for each annual publication.

\footnotetext{
${ }^{1}$ http://grupodeestudiosobrecuerpo.blogspot.com
} 
This work of recording and protecting cultural material on performing artssd makes part of the Intangible Cultural Heritage, defined by UNESCO [1]. Intangible cultural heritage includes traditions or living expressions inheritance of our ancestors, and that can be transmitted to our descendants. Among them we can list the rituals, performing arts, social practices, and festive events [2], [3].

Although there are different works in Argentina on recording the cultural heritage [4], [5], [6], none of them focuses on the intangible cultural heritage specialized on performing arts. This work introduces a collaborative platform that stimulates collective knowledge building and knowledge sharing in a network of performers, artists, and audience. It uses semantic web technologies to represent the domain in a way that enables computer-based processing. Thus, it provides support to generate semantic queries and for the derivation of new information (i.e., semantic reasoning). These semantic queries allow new levels of information that for a person would be very complex to obtain in a traditional manner. Once the knowledge base is consolidated, this information can also be used by any institution that specializes in performative activities.

Knowledge formalization requires certain levels of information quality. Quality assurance can be done manually, using information technologies, or through a combination of both. The direct participation of experts in performing arts activity is a key factor. It can be done inviting the performers, artists and other participants of the performing arts (including public) to load and generate information based on firsthand knowledge manually.

Nodos is a research project conducted as a citizen science. A citizen science project involves the community in tasks related to scientific activities. Such tasks are linked to classification, creation, curation or analysis of information. People from the community that participated actively during the development of the process become citizen scientists [7], [8].

In this work, we have detected three main challenges. First, people who use the platform for recording the performing arts should not need any extra skill apart from being able to use internet and accessing to any kind of website. Second, the system must provide user interfaces and tools to ensure that the data will be generated in computer readable format. Lastly, the project needs to motivate people to continue improving the catalogue.

In this article, we introduce the first version of a semantic ontology on performing arts called NodosOntology. The ontology's first version allowed us to describe main concepts related to intangible cultural heritage on performing arts such as plays, people, artists groups and the semantic relationships among them. Additionally, we introduce Nodos as a semantic wiki that articulates NodosOntology and is easily accessed and used. As a way to conclude this research paper, we present a usability evaluation for performing arts community members. Also, we showed relevant conclusions made through this research and further detailed work.

\section{The performing arts catalogue}

Every year in the city of La Plata, Argentina, many events linked to performing arts take place. This type of cultural material is what UNESCO determines as Intangible Cultural Heritage [1], [2]. In this regard, GEC group has been working on collective and individual research in order to understand and to account performing arts' current situation in the city of La Plata. Hence, with this project we seek to convene and to compile information regarding performing arts in the city. The project aims to document and advertise performing arts' intense and prolific activity, and to create in return an archive that compels relevant information and that expands year after year.

The catalogue needs to reflect important information of the different stakeholders that compose performing arts scene in the city of La Plata (i.e. actors, performers, dancers, theaters, etc.). In recent times, GEC has tried to complete data collection for the catalogue using manual processes made up of surveys, content curation, and manual compilation. However, the number of artist, groups, and works is so extensive that the task could not be accomplished and the catalogue was finished out of the deadline. Thus, for the creation of this new catalogue, we have planned a series of stages that starts with the description of basic elements and concepts that we want to specialize in (Nodos) and then it continues 
with the construction and extension of each of one of this terms. As a first step, we introduced the basis for the description of works, people, groups of artists and artistic events.

\section{Nodos as a citizen science project}

Citizen science is a scientific activity in which non-professional scientist voluntarily participate in the collection, analysis, and dissemination of data in scientific projects [7], [9]. There are three distinctive features common to all successful citizen science projects: tools, community, and method.

Tools let researchers define tasks (classification, sampling, tagging, and transformation) and distribute them among volunteers. Some tools support only one type of tasks. GalaxyZoo ${ }^{2}$, for example, is a wellknown classification tool (specialized to galaxy classification). Mosquito Alert ${ }^{3}$ is both a sampling (i.e., to take samples) and a classification tool.

All crowdsourcing endeavors (citizen science being one particular type) depend on a large, active and diverse community. Some citizen science projects count on their own, unique, community of volunteers, such is the case of FoldIt ${ }^{4}$ with its community of more than 13.000 volunteers (players). Other projects share their volunteer communities. In Zooniverse ${ }^{5}$, many projects (approximately 50 at the time of this writing) share a larger volunteer base.

Although citizen science is a young and still evolving discipline, much has already been learned from past successful and unsuccessful experiences. Successful projects have well-defined methods that help in the process of project selection and definition. These methods must attract, engage, educate, and acknowledge volunteers, they must also support the researcher along with a diverse range of tools, community directions, and action routes in order to create a citizen science platform.

Cientopolis.org is a multidisciplinary project that aims to the creation of replicable citizen science platforms. A set of reusable tools that allows researchers to define sampling protocols and that currently focuses on sampling components available in modern phones (camera, microphone, GPS, gyroscope). The open source classification builder created by the Zooniverse project (called Panoptes), and ad-hoc citizen science games like GalaxyConqueror [10]. Gamification is Cientopolis' key approach to attract and engage volunteers.

Nodos is introduced as another project that uses the Cientopolis platform. In the case of Nodos, the scientific team is the one defined by GEC group. They have specific research topics that are related to performing arts. The method used in this research was the recording of performing arts activities, and the active participation of community. This participation in Nodos refers to the capacity that citizens have to complete, edit, curate and use the catalogue when needed. People involved in the community of performing arts are the citizen scientists. The audience, artists and other people involved in the process of creation and development of scenic arts are part of the relevant community for the project. This means a large number of people can work for this research project. The Nodos approach aims to involve community in the construction of a collaborative repository about performing arts. The community can use any of the information hosted in Nodos. This combination requires a collaborative, easy-use and accessible approach.

\section{Nodos: Collaborative content on performing arts}

Collaborative editing is considered as a group activity which its objective is to produce content and information through single individual contributions. The group pursues a common goal. By working

\footnotetext{
${ }^{2}$ http://www.galaxyzoo.org - Last accessed October 1st, 2016

${ }^{3}$ http://www.mosquitoalert.com - Last accessed on October 1st, 2016

4 http://fold.it - Last accessed on October 1st, 2016

5 https://www.zooniverse.org - Last accessed on October 1st, 2016
} 
collaboratively, the complexity of the task is reduced since the results are obtained through contributions made by different people, rather than the ones only made by a single person [11].

In Nodos, we adopted "the wiki way" performing arts. In a similar way to the one in which Wikipedia allows its users to participate in the creation and editing of encyclopedic articles, Nodos makes users active participants in the creation and edition of collaboratively articles regarding works (plays), performers, actors, dancers, groups of artists and all kinds of information associated with performing arts.

\section{NodosOntology}

NodosOntology was developed by a multidisciplinary group of researchers with different academic backgrounds. The peculiarity of this group is that all members have an artistic career linked to performing arts. The richness of this diversity combines different levels of expertise: the performing arts study field and the semantic web and knowledge representation field. The ontology members of the design team included two anthropologists, a journalist, a choreographer, and a computer scientist. All of them had an artistic profile that combines theatre, dance and performances. Although NodosOntology was developed in Spanish, in this article, we provide the names of classes and properties in both languages English and Spanish.

To develop NodosOntology, the project followed a design strategy based on four steps: the first step was focused on the process of (i) learning and discovering abstractions, the second one dealt with (ii) the description of concepts and concepts' relationships, the third step was related to (iii) the different processes for selecting data types, and the last one dealt with (iv) data formalization using OWL.

\subsection{Learning and discovering abstractions}

The objective of this first stage was to provide basic knowledge about abstraction and modeling skills to the group of performing arts experts (members of the GEC group). Primarily, the task consisted on making a model of candidate concepts used in performing arts and then group them into classes. From the selected concepts and the creation of groups, the next step was to detect these classes as common structural elements (e.g. the name), and then to analyze the relationships between classes and concepts.

\subsection{Description of concepts and concepts' relationships}

This second stage spotted works, cultural spaces, groups, and individuals as main concepts. The greatest difficulty that arose in this stage was the characterization of concepts with multiple relationships. For example, "Roles" that describe the role a person can also be fulfilled with another concept. In the case of a play, a person can fulfill the role of an actor or of a director (or both).

\subsection{Different processes for selecting data types}

The challenges for this stage were focused on determining whether the value of the attributes should be a free-form text or should be a modeled structure of the new concepts. For example, the "Date" data type for the release date of a work or performance was easy to assign (a well-formatted string representing a Date). However, in other cases, it must be taken into account the relationship between the capacity of achieving a detailed description for an ontology and the possibility of using it for people who do not necessarily have the skills for analyzing the content description format. An example of the latter case was the need to describe the rehearsal process. For example, for a play it was necessary to list various

6 "the wiki-way" was introduced by Leuf \& Cunningham [16] 
elements such as the frequency of rehearsal, the number of hours spent and the preparation time until the premiere. All of these required the definition of a new concept in the ontology.

\subsection{Data formalization using OWL}

RDF / OWL was used for this formalization. The latter part was largely carried out by a team member with an academic profile linked to computer science and with previous experience as a semantic engineer.

Core classes of this ontology are Play, Person, Venue (cultural space) and Group. However, other classes that represent the relationships between the major classes also appeared. The purpose of general representation possessing these classes is as follows:

- Play: A play is the representation of a performative expression. Dance, theater and performances plays are included in this class.

- Person: Anyone who is involved in some way with the performing arts. In this domain, people (except the public), are linked to the other elements by roles.

- Group: Represents a group of people that are identified by a particular group identity. Groups take place of any person who is part of a collective representation.

- Participation: This class represents the relationship between people and a play, or people and a group.

- Frequency: Represents how often a play is presented to the public. Three levels of frequency are defined, each of them can be described as another class:

- Season: It represents a period with two or more presentations. It has both a beginning date and an end date. Additionally, a season includes a reference to a venue. For example, a seas on could run from 02.10.2015 to 27.11.2015 every Friday in the theater "The Bowler."

- Special Show: It represents a sporadic presentation on a specific day.

- Festival Presentation: In this case, the frequency is usually of one day, but it includes the link with a Festival. (Festivals are not included in this preliminary version of the ontology).

The definition of these classes and the properties of NodosOntology are detailed in Tables 1 and 2.

Table 1. Classes and DataProperties - the Spanish name of each of them are written between brackets.

\begin{tabular}{|l|l|}
\hline Class & DataProperties \\
\hline Play & $\begin{array}{l}\text { name (nombre):String - premiereDate (fechaDeEstreno): Date - } \\
\text { synopsis(sinoposis):String - motivation(motivación): String - subject (tema):String - } \\
\text { methodology (metodología):String }\end{array}$ \\
\hline Person & $\begin{array}{l}\text { name(nombre):String - curricularReview (reseñaCurricular):String - birthdate } \\
\text { (fechaDeNacimiento): Date }\end{array}$ \\
\hline Group & name:String - creationDate:Date - review(reseña):String \\
\hline $\begin{array}{l}\text { Participation } \\
\text { (Participación) }\end{array}$ & beginningDate(fechaDeInicio): Date - endDate(fechaDeFin):Date - role(rol):String \\
\hline Season (Temporada) & beginningDate(fechaDeInicio): Date - endDate(fechaDeFin):Date - \\
\hline $\begin{array}{l}\text { FestivalPresentation } \\
\text { (PresentaciónEnFestival) }\end{array}$ & beginningDate(fechaDeInicio):Date - endDate(fechaDeFin):Date \\
\hline $\begin{array}{l}\text { SpecialShow } \\
\text { (FunciónEspecial) }\end{array}$ & reason(motivo):String \\
\hline Venue (Espacio) & name(nombre):String - \\
\hline Festival (Festival) & $\begin{array}{l}\text { name(nombre):String - description(descripción):String - methodology(metodología): } \\
\text { String }\end{array}$ \\
\hline
\end{tabular}


Table 2. Semantic Properties: for each property is detailed the description and the domain and range. The original name in Spanish appears between brackets.

\begin{tabular}{|l|l|l|}
\hline ObjectProperty & Description & Domain (D) y Range (R) \\
\hline $\begin{array}{l}\text { madeIn } \\
\text { (realizadoEn) }\end{array}$ & Venue where a play was or is done. & $\begin{array}{l}\text { D:Season U FestivalPresentation U SpecialShow } \\
- \text { R:Venue }\end{array}$ \\
\hline $\begin{array}{l}\text { festival } \\
\text { (festival) }\end{array}$ & It relates a play with a festival & $\begin{array}{l}\text { D: FestivalPresentation } \\
\text { R:Festival }\end{array}$ \\
\hline $\begin{array}{l}\text { participation } \\
\text { (participación) }\end{array}$ & Participation of a person & $\begin{array}{l}\text { D: Group U Play U Festival } \\
\text { R: Participation }\end{array}$ \\
\hline $\begin{array}{l}\text { aPlayBy } \\
\text { (unaObraDe) }\end{array}$ & It relates the authorship & $\begin{array}{l}\text { D: Play U Festival } \\
\text { R: Group U Person }\end{array}$ \\
\hline $\begin{array}{l}\text { participation } \\
\text { (enCalidadDe) }\end{array}$ & The role in a participation & $\begin{array}{l}\text { D: Participation } \\
\text { R: Role }\end{array}$ \\
\hline $\begin{array}{l}\text { madeBy } \\
\text { (efectuadoPor) }\end{array}$ & Relates a person of a participation. & $\begin{array}{l}\text { D: Participation } \\
\text { R: Person }\end{array}$ \\
\hline $\begin{array}{l}\text { picture } \\
\text { (foto) }\end{array}$ & Elements from the ontology with a picture & $\begin{array}{l}\text { D: Thing } \\
\text { R: Picture }\end{array}$ \\
\hline
\end{tabular}

\section{Nodos as a semantic wiki}

Nodos is a customization of the Semantic Mediawiki (SMW) for NodosOntology. The SMW is an extension to the Mediawiki engine that complements it with a semantic information management layer. In addition to the functionality of the traditional wiki, SMW adds a semantic model underlying the traditional model of the wiki. This semantic model is defined on top of the standards of the Semantic Web, and it is compatible with RDF. Thus, a traditional wiki that has an editable hypertext now may contain semantic queries about their knowledge base and can export its information to another agent in the Linked Open Data cloud. For example, when labeling an article (e.g. Paris) with a category (e.g. European Country) the engine generates an RDF triplet that relates Paris with the European Country (Paris rdf: type EuropeanCountry). In SMW, categories are defined as RDF classes. With SMW, the articles also may be related to semantic properties (e.g. Paris isCapitalOf France).

The biggest difference Nodos has with a traditional wiki is the use of NodosOntology ontology specification. In Nodos, Plays, Groups, People and other concepts of the ontology are represented as wiki articles that have semantic relationships that describe the content of the article, as well as their relationships to other articles.

\subsection{Creating and editing elements in Nodos}

To add new articles to Nodos, a set of forms based on the Semantic Form plugin are offered. Semantic Forms is a Mediawiki extension that provides simple semantic forms to create and edit items with a userfriendly interface. The current version of Nodos offers semantic forms to create Plays, People, Groups and Venues. Figure 1 shows the semantic form to create and edit Plays. In the picture, fields are in Spanish: "Foto" for picture property, "Fecha de estreno" for premierDate, "una obra de" for aPlayBy, etc. 


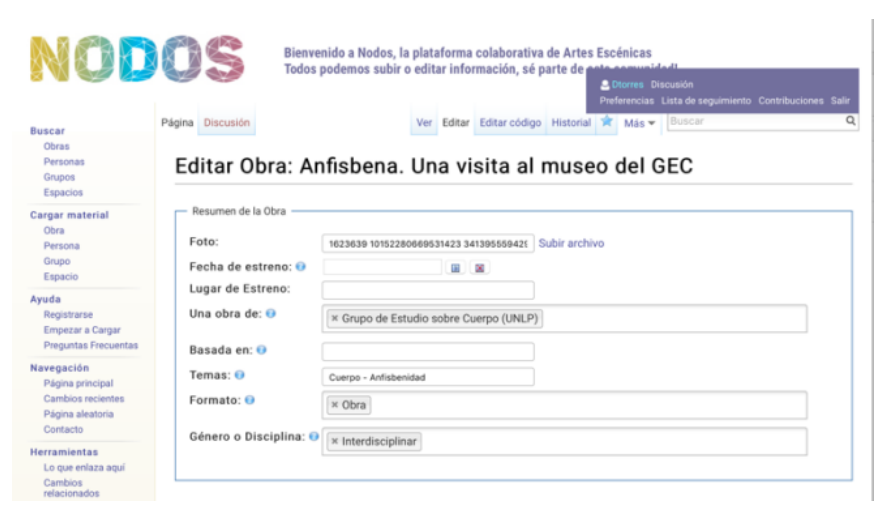

Figure 1. Form for a Play

Once the user saves the changes or creates a page for a Play, the page in an understandable manner can be seen. For example, Figure 2 shows the page of the work that was published in the form of Figure 1. The title of the Play is the page title showed at the top of Figure 2, then on the left of the Figure is displayed the content and text of each element. On the right side of the page, a user can see a box containing a representative picture of the work and below it is shown a summary of the Play (Infobox).

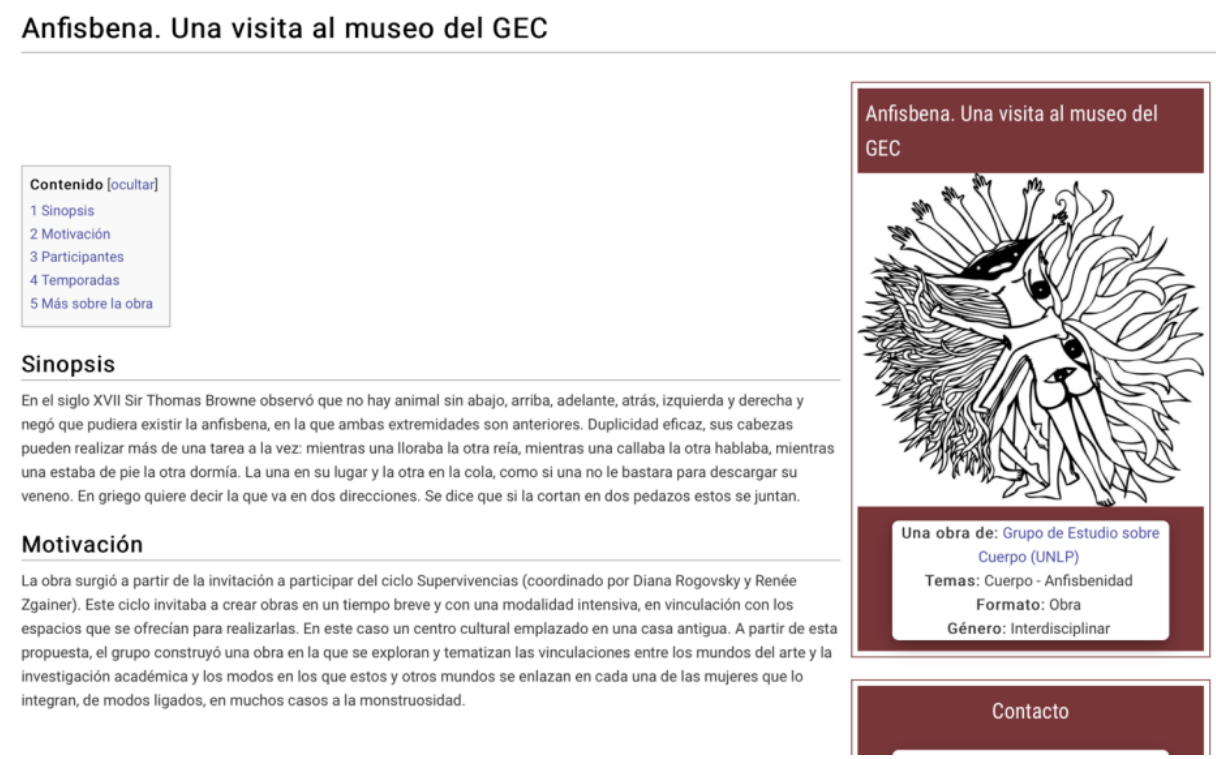

Figure 2. View of a Play

In addition, the semantic relationships of an article can be seen and navigated. SMW includes a view where one can see the semantic relationships of any article. These views make it possible to understand the semantic structure and the concepts that are involved in each one of the articles. In Figure 3 we can see the semantic properties of the article "Anfisbena. Una visita al museo del GEC", the play that is shown in Figure 2. 


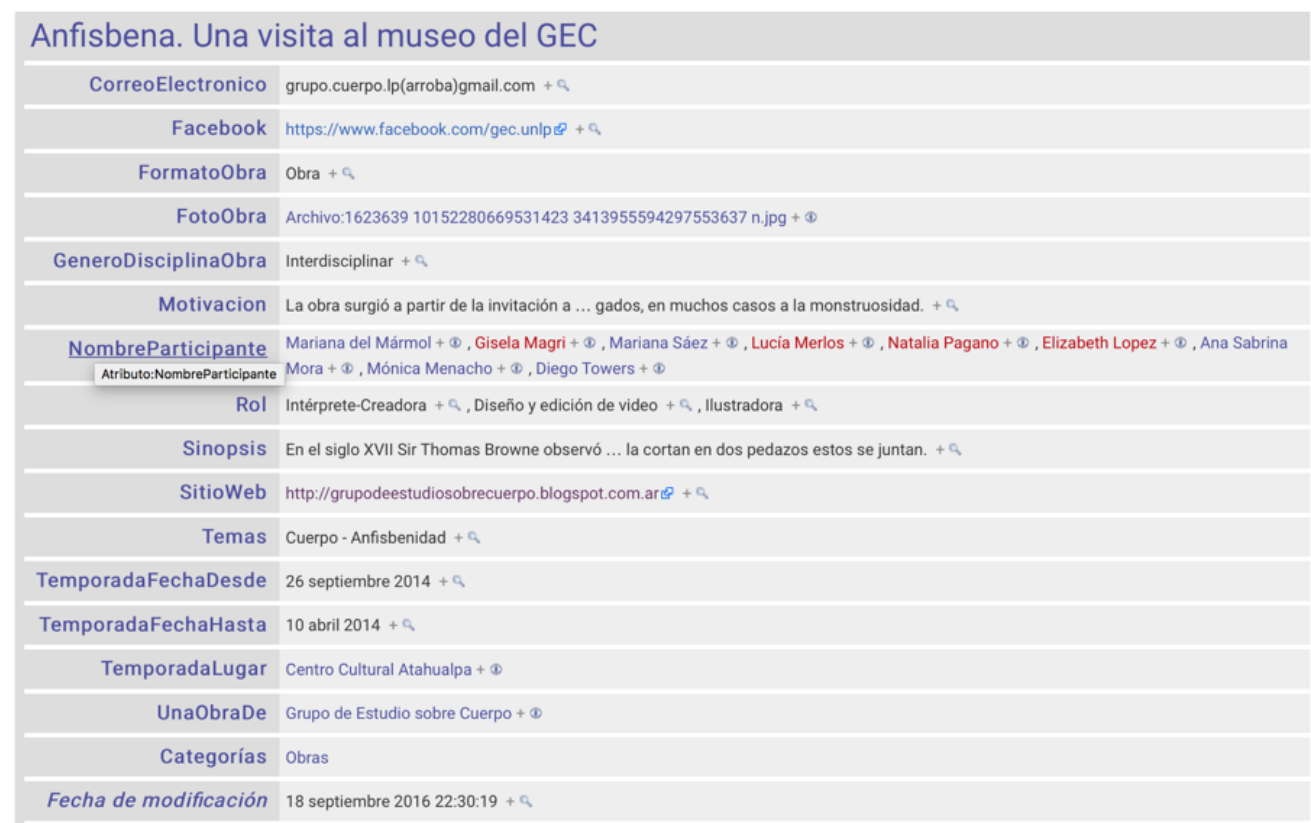

Figure 3. List of properties and their values for a Play.

\subsection{Dynamic linking among articles}

One of the included features in Nodos is the dynamic linking of items during the editing process. Those articles that are related to semantic properties are enriched in its content through semantic queries without the user interaction. For example, the list of participants in a Play. When a user includes a new participant in the Play form, Nodos dynamically updates the article of the Person or the Group that is involved. This enrichment is performed automatically.

Figure 4 shows the participation in the play of the previous example. In it, you can see that Mariana del Mármol participated as "Interpret-Creator" (Intérprete-Creadora). When viewing the article by Mariana del Mármol in Nodos, the section "Participation in plays" section will have the corresponding input.

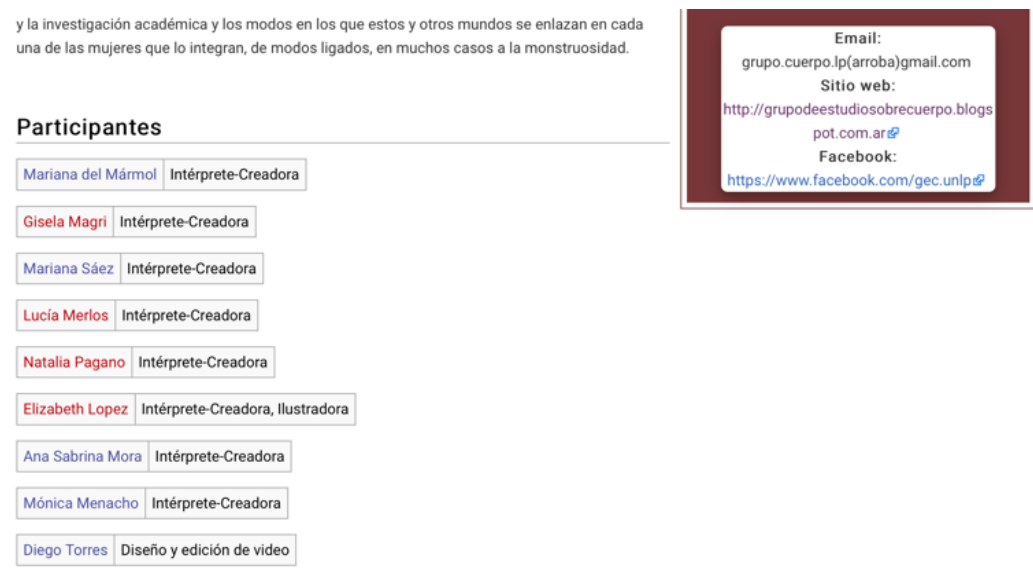


Figure 4. Participation (Play)

Automatic update of People articles is achieved by the use of semantic queries. The participation in plays for a person is obtained by the following semantic query 7 :

$\{$ \{\#ask: [ [ParticipaDeObra: :+] ] [ [NombreParticipante: : \{ \{SUBJECTPAGENAME \} \} ] ]

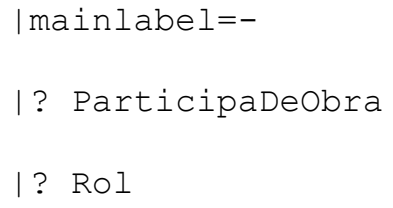

The query gets the list of all participation (ParticipaDeObra) elements in the ontology where participant name property (NombreParticipante) is bound to the current page (the person page). From this element, it is listed the play/he takes part (ParticipaDeObra) and her/his role (Rol).

\section{Related work}

One of the works on semantic definitions related to cultural heritage is introduced by Hernández Carrascal [12], where a Cultural Heritage ontology under W3C recommendations is created. However, the ontology does not include the intangible cultural heritage artifacts as defined in Nodos.

The work of Stanley and Astudillo [13] proposes a definition of an ontology that represents the intangible cultural heritage and that uses a semantic wiki. In this case, the chosen intangible cultural heritage is linked to festivals, and the semantic wiki engine they use is Ontowiki. The ontology presented in this paper could be supplemented by Stanley and Astudillo as both deal with intangible cultural heritage, but with two slightly differences in sub domains.

Additionally, in spite the wiki Beeld in Geluid 8 is not focused on intangible cultural heritage, it presents information related to artists, T.V. shows, and genres. Although it is not about performing arts as Nodos, it includes many definitions that can be used to improve the NodosOntology ontology.

Finally, a SMW is used to make semantic annotations on cultural heritage based on historical books on the work of Witte et al. [14].

\section{Nodos in the OLD context}

Many of the concepts introduced in Nodos can be related to concepts developed in other ontologies and vocabularies used in the Linked Open Data (LOD) cloud. The Nodos platform and the information contained in the semantic wiki are inserted into the Linked Open Data context. Additionally, the information stored in Nodos is under the Creative-Common Attribution-ShareAlike 4.0 License.

Regarding the matter related with vocabulary recycling, the Theatre Onthology ontology by Luke Blaney describes plays in a similar way to Nodos. Moreover, FOAF (Friend Of A Friend) is a machine-

\footnotetext{
7 The properties in the semantic wiki are translated to Spanish.

${ }^{8}$ http://beeldengeluidwiki.nl/index.php/Hoofdpagina
} 
readable standard ontology to describe information regarding people who may well apply to the management of people within Nodos. Schema.org also proposes several useful ontologies. The equivalence of ontologies is detailed in Table 3, and the equivalence in properties is detailed in Table 4.

Table 3. Equivalent ontologies

\begin{tabular}{l|l}
\hline Class & Equivalence \\
\hline Person & http://xmlns.com/foaf/0.1/Person \\
\hline Play & http://lukeblaney.co.uk/semweb/theatre\#Production \\
\hline Season & http://lukeblaney.co.uk/semweb/theatre\#Season \\
\hline Venue & http://lukeblaney.co.uk/semweb/theatre\#Venue \\
\hline Group & $\begin{array}{l}\text { http://lukeblaney.co.uk/semweb/theatre\#ProductionCompany // } \\
\text { https://schema.org/TheaterGroup }\end{array}$ \\
\hline Participation & http://vocab.org/participation \\
\hline Event & http://lukeblaney.co.uk/semweb/theatre\#event \\
\hline
\end{tabular}

Table 4. Equivalence between properties

\begin{tabular}{l|l|l}
\hline Class & DataProperty & Equivalent \\
\hline \multirow{4}{*}{ Person } & name & foaf:term_firstName \\
\cline { 2 - 3 } & surname & foaf:term_lastName \\
\cline { 2 - 3 } & birthday & foaf:term_birthday \\
\cline { 2 - 3 } & title & theatre: title \\
\cline { 2 - 3 } & premiereDate & theatre :premiere \\
\cline { 2 - 3 } & subject & theatre:subject \\
\hline \multirow{4}{*}{ Season } & aPlayBy & theatre:based_on \\
\hline Venue & beginningDate & theatre:put_on_by \\
\cline { 2 - 3 } & endDAte & https://schema.org/startDate \\
\hline Group & name & https://schema.org/endDate \\
\hline & & theatre:venue \\
\cline { 2 - 3 } & creationDate & https://schema.org/foundingDate \\
\cline { 2 - 3 } & provenanceGroup & https://schema.org/foundingLocation \\
\hline \multirow{2}{*}{ Participation } & beginningDate & https://schema.org/startDate \\
\cline { 2 - 3 } & endDate & https://schema.org/endDate \\
\cline { 2 - 3 } & role & theatre:position \\
\hline
\end{tabular}

On the other hand, Semantic Mediawiki allows access to information contained in an understandable way for computers, which is in RDF format. For example, the RDF view of the Work "Anfisbena. Una visita al museo del GEC " is shown in Table 5.

Table 5. RDF Export of a Play

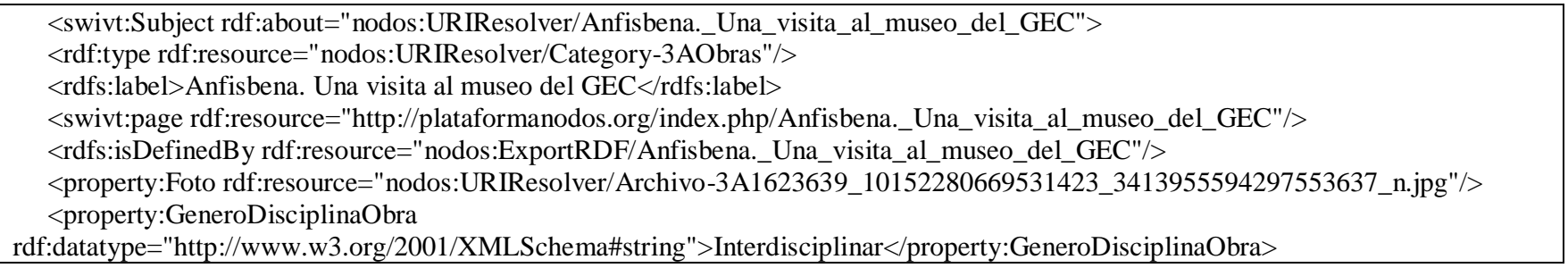


〈property:Motivacion rdf:datatype="http://www.w3.org/2001/XMLSchema\#string">

La obra surgió a partir de la invitación a participar del ciclo Supervivencias (coordinado por Diana Rogovsky y Renée Zgainer)..

$</$ property:Motivacion>

<property:NombreParticipante rdf:resource="nodos:URIResolver/Mariana_del_M-C3-A1rmol"/>

\section{Evaluation}

In this section, we analyze the usability and understanding of Nodos approach with people from the performing arts community. The evaluation is not only conducted to understand the preferences of the artistic community, but also to assess the system's ease of use and to analyze the effort required for participation.

\subsection{Methodology}

We invited different ranges of people directly related to performing arts (e.g. theater directors, dancers, choreographer, actors, and performers). Each one of them had to develop the following activities:

1. Create a Person page about herself/himself:

a) To make sure that the page is not already created.

b) To create or to edit this new page with her or his information.

2. Create a Play page about its plays:

a) To make sure this page is not already created.

b) To create or to edit this page with new information. Use participation where necessary.

3. Create a Group page

a) To make sure this page is not already created.

b) To create or to edit this page with new information. Use participation where necessary.

4. Repeat the process for as long as you want.

After the activity, each person answered a short survey that had the following questions: 1) What was the most interesting thing to do? 2) Were the forms clear? 3) Did you choose to leave incomplete things? Why? 4) Based on the forms you filled in, is there any information that you think is not required or not relevant? Why? 5) Is there any information that you think it requires to be explained with more detail? Which one?

The evaluation was posted in the online version of Nodos (Nodos platform is hosted in www.plataformanodos.org). This evaluation took place in 2016 during two opportunities: The first time the evaluation took place was on July $2^{\text {nd }}$, and the second time it took place was on October $25^{\text {th }}$. When the evaluation was displayed for the first time, Nodos had 80 articles related to Plays that were collected by GEC before Nodos. Then, at the time of the second display Nodos had 115 articles. The participants were 12 females and 6 males. From the 18 participants that took the survey, five persons were closer to theater related arts while the others were closer to dance arts and performances.

\subsection{Evaluation results and learned lessons}

As all the questions were open, above we will describe main trends found in the answers:

- What was the most interesting thing to answer? Most of the surveyed people showed a prominent interest in the fact that most of the information related to performing arts was centralized in a portal. Additionally, the similarity with Wikipedia's style and interface was a valuable aspect for respondents.

- Were the forms clear? In general, the forms for creating or editing articles were clear. No mistakes were detected when checking respondents' answers. However, some of the participants 
expressed that the "upload picture" tab included excessive information and this made it difficult to understand.

- Did you choose to leave incomplete things? Why? Almost all the respondents left spaces without information. For example, there were many cases in which respondents created pages of a Play or a Person, and left many spaces in blank. Many respondents only wrote information, such as name, picture, and other information. According to them, the main reason was the amount of time each one of the task takes. One of the participants said that she was working on her personal page because she works within a group of artists while other person, that works for the same group as her, was working on the group page. Finally, only one participant left information of old plays (i.e. plays that are not currently available)

- Based on the forms you filled in, is there any information that you think is not required or not relevant? Why? All of the participants agreed that all the information required in the forms was necessary and relevant.

- Is there any information that you think it requires to be explained with more detail? Which one? Most of the answers showed some discomfort with the option for roles in the forms. Many respondents stated that the option for roles had to be more precise, and that it needs to be fixed or the form should leave this field as an open answer. For example, "actor", "actor" and "actress" appeared as different values for a same role. Another group of people required to explain the link between person and group. Moreover, most of the participants also expressed the necessity of having separated pages for Events and Festivals. The evaluation left us important experiences and various learned lessons. The similarity of our forms with Wikipedia's interface and style helped us to transfer the idea of having an encyclopedia about performing arts. In addition to this, most of the participants understood that as in Wikipedia, this project is achievable and it encouraged them to continue participating actively in the encyclopedia's collaborative creation. Additionally, the use of semantic connections among the concepts generated in the users an idea of the automatic addition of information in the Person pages. This is possible thanks to the semantic queries included in the Person forms. This semantic queries are obtained from other resources in the wiki and from the information that is semantically linked to that person. The query generates a chart with all the participation entries for that person. For example, when a user includes in play article of "Hamlet" a new participation of "Richard Holmes" as "actor", automatically the article of "Richard Holmes" appears improved with the participation as actor in "Hamlet".

However, Nodos has several aspects to be improved. Some of them related to the complexity to upload media or the amount of required information. In the evaluation, the time to complete a page was one of the most significant problems. We consider that a page is in continuous improvement and that its edition takes several iterations from different users. The Participants' opinion regarding long time that it takes to fill in the information, must be considered as a preliminary information to manage the motivation, and as a base for future edition of pages that are already created. This includes the improvement of the information's quality and the correct fulfillment of information. In order to conclude the various procedures we used to test Nodos, A SUS survey [15] was also taken in order to have a usability reference. The obtained value was 83.9 on average, which is a good usability value.

For future research works, we believe a strategy to generate different kinds of motivation in Nodos is going to be needed. This motivation might be explored and boosted through gamification techniques.

\section{Conclusions and further work}

In this paper, we have presented a proposal for the registration and documentation of performing arts as intangible cultural heritage. Also, we presented an empiric evaluation of the approach presented throughout this paper. This project is presented as part of an interdisciplinary work, which its first version (NodosOntology) was a semantic representation of performing arts and NodosOntology's usability in different scenarios.

We also included the semantic wiki Nodos (accessible by http://plataformanodos.org) as a tool to articulate the ontology and to record and edit information regarding performing arts in a simple way. 
Nodos allows the immediate participation of people involved in the performing arts scene. As presented in this article, the definition of ontology and semantic wiki are the product of an incipient work. As future work, it should be considered using other vocabularies to incorporate NodosOntology such as FOAF, DoublinCore or among others.

The evaluation showed that to achieve a similarity with Wikipedia is an achievable milestone, and semantic connections show users how automated creation of information works and it may improve the human workload. However, there are several usability aspects to be improved and also new proposals to be developed as further works.

\section{Acknowledgements}

This work is partially supported by an AWS in Education Research Grant award.

\section{References}

[1]E. L. Bin Ong et al., "Convention for the Safeguarding of the Intangible Cultural Heritage," 2010.

[2]UNESCO, "What is Intangible Cultural Heritage?," 2016.

[3] Universidad Pública de Navarra, El patrimonio cultural inmaterial: Ámbito de la tradición oral y de las particularidades linguísticas, 2014.

[4]Ministerio de Cultura Presidencia de la Nación, "Instituto Nacional de Musicología 'Carlos Vega'," 2016 [Online]. Available: https://www.cultura.gob.ar/institucional/organismos/museos/instituto-nacional-demusicologia-carlos-vega/. [Accessed: 29-Apr-2016].

[5]C. Vega, Panorama de la música popular argentina: con un ensayo sobre la ciencia del folklore. Instituto Nacional de Musicología Carlos Vega, 1944.

[6]C. Vega and E. M. Chá, Las danzas populares argentinas, vol. 1. Instituto Nacional de Musicología“ Carlos Vega," Dirección Nacional de Música, Secretaría de Cultura, Ministerio de Educación y Justicia, 1986.

[7]S. Elwood, M. F. Goodchild, and D. Z. Sui, "Researching volunteered geographic information: Spatial data, geographic research, and new social practice,” Ann. Assoc. Am. Geogr., vol. 102, no. 3, pp. 571-590, 2012.

[8] J. Silvertown, “A new dawn for citizen science,” Trends Ecol. Evol., vol. 24, no. 9, pp. 467-471, 2009.

[9]R. Louv, J. W. Fitzpatrick, J. L. Dickinson, and R. Bonney, Citizen science: Public participation in environmental research. Cornell University Press, 2012.

[10] M. Celasco, J. I. Yañez, A. Fernández, D. Torres, and A. Díaz, "Galaxy Conqueror: aplicando técnicas de ciencia ciudadana y gamificación en la búsqueda de galaxias," in IEEE Décimo Primera Conferencia Latinoamericana de Objetos y Tecnologías De Aprendizaje (Laclo2016). San Carlos, Costa Rica., 2016.

[11] P. B. Lowry, A. Curtis, and M. R. Lowry, "Building a taxonomy and nomenclature of collaborative writing to improve interdisciplinary research and practice," J. Bus. Commun., vol. 41, no. 1, pp. 66-99, 2004.

[12] F. Hernández-Carrascal, "Ontología del patrimonio de Cantabria," El Prof. la Inf., vol. 17, no. 1, pp. 92-98, Jan. 2008.

[13] R. Stanley and H. Astudillo, "Ontology and Semantic Wiki for an Intangible Cultural Heritage Inventory," in Computing Conference (CLEI), 2013 XXXIX Latin American, 2013, pp. 1-12.

[14] R. Witte, T. Gitzinger, T. Kappler, and R. Krestel, "A semantic wiki approach to cultural heritage data management," in Proc. Workshop Language Technology for Cultural Heritage Data, 2008, pp. 61-68.

[15] J. Brooke, "SUS: A quick and dirty usability scale," in Usability evaluation in industry, P. W. Jordan, B. Weerdmeester, A. Thomas, and I. L. Mclelland, Eds. London: Taylor and Francis, 1996, pp. 4-7.

[16] B. Leuf and W. Cunningham, The Wiki Way: Quick Collaboration on the Web. Addison-Wesley Professional, 2001.

\section{About the authors}

\section{Diego Torres}

Licenciado en Informática. Doctor en Ciencias Informáticas de la Univerisad Nacional de La Plata, Argentina. Docteur de l'Université de Nantes, Francia. Jefe de Trabajos Prácticos de la Universidad Nacional de La Plata. LIFIA, Centro Asociado CIC, Facultad de Informática, Universidad Nacional de La Plata - Profesor adjunto, Deptartamento de Ciencia y Tecnología, Universidad Nacional de Quilmes. 
Investigador adjunto asociado, Comisión Investigaciónes Científicas de la Provincia de Buenos Aires. La Plata, Argentina.

\section{Alicia Díaz}

Licenciado en Informática, Universidad Nacional de La Plata. Doctor en Informática, Université Henry Poincaré Nancy 1, Francia. Profesor Titular, Universidad Nacional de La Plata. LIFIA, Centro Asociado CIC, Facultad de Informática, Universidad Nacional de La Plata. La Plata, Argentina.

\section{Virginia Cepeda}

Licenciatura en Sistemas (alumno). Facultad de Informática, Universidad Nacional de La Plata. La Plata, Argentina.

\section{Facundo Correa}

Licenciatura en Sistemas (alumno). Facultad de Informática, Universidad Nacional de La Plata. La Plata, Argentina.

\section{Alejandro Fernandez}

Licenciado en Informática, Universidad Nacional de La Plata. Doctor en la FernUnivesität Hagen, Alemania. Profesor adjunto en UNLP. LIFIA, Centro Asociado CIC, Facultad de Informática, Universidad Nacional de La Plata. La Plata, Argentina. 